\title{
Perspectivas contemporâneas do ensino de línguas e literaturas
}

A revista $A$ Cor das Letras, em 2017, tornou-se quadrimestral e, a partir de então, passou a ter um número anual dedicado ao Ensino de Linguas e Literaturas, com o objetivo de fomentar o debate em torno de questões contemporâneas que envolvam a problemática do ensino em diferentes contextos.

No Brasil, tem crescido o número de pesquisadores interessados em desenvolver pesquisas aplicadas ao ensino, especialmente à Educação Básica. Os Mestrados Profissionais são um exemplo do interesse dos pesquisadores e do Ministério da Educação (MEC), por meio da Coordenação de Aperfeiçoamento de Pessoal de Nível Superior (CAPES), em aproximar as universidades da escola básica, tendo em vista a qualificação de professores em exercício nas escolas públicas. O Programa Institucional de Bolsa de Iniciação à Docência (PIBID) é outra inciativa que tem aproximado os cursos de licenciatura à realidade da Educação Básica e promovido múltiplos aprendizados. Essas iniciativas nos ensinam que não é mais possível formar professores nas universidades sem vivenciar o cotidiano escolar e buscar alternativas para enfrentar os desafios que ele impõe aos profissionais da Educação.

As universidades públicas - especialmente aquelas que têm cursos de formação de professores - precisam dar respostas para a triste realidade da Educação Básica no Brasil. Há pesquisas de qualidade, com alternativas criativas para o ensino de línguas e literaturas, sendo desenvolvidas no Brasil e no exterior; os resultados de tais pesquisas, entretanto, não têm sido divulgados como é desejável. É com o intuito de promover o diálogo entre os pesquisadores e demais interessados na área de ensino de línguas e literaturas que a revista $A$ Cor das Letras publica um número (número 3, do volume 18 (2017)) dedicado exclusivamente a essa temática.

Esse número reúne dezoito artigos escritos em língua portuguesa, inglesa e espanhola. Os autores são pesquisadores de diversas universidades brasileiras, e grande parte dos textos são resultado de pesquisas de mestrado e doutorado.

O primeiro artigo desse número é de autoria de Dalve Oliveira Batista-Santos e Dimas Henrique Pereira de Oliveira Silva - ambos da Universidade Federal do Tocantins -, intitulado $A$ escrita sob o olhar do aluno no ensino médio: representações e reflexões. Os autores apresentam uma pesquisa baseada nos Novos Estudos do Letramento, concentrando-se nas representações de alunos do Ensino Médio e suas competências escritoras, levando em consideração o seu ingresso no Ensino Superior. A pesquisa foi desenvolvida numa escola do município de Palmas-TO. Trata-se de um estudo relevante, pelas reflexões que proporcionou acerca das práticas de escrita utilizadas por alunos.

$\mathrm{O}$ artigo intitulado $A$ motivação para a leitura na escola: contribuições do ensino de literatura, de autoria de André Luís Machado Galvão e António Carvalho da Silva, da Universidade do Minho, Portugal, aborda a importância da leitura no mundo contemporâneo e como ela tem sido trabalhada na escola, considerando em que termos o ensino de literatura pode ser motivador da formação do gosto pelo ato de ler. Os autores argumentam que o 
investimento no letramento literário é uma opção para formar leitores críticos e autônomos.

O terceiro artigo é de autoria de Isnalda Berger, da Universidade Estadual de Feira de Santana, e Úrsula Cunha Anacleto, da Universidade do Estado da Bahia, intitulado Ensino de língua portuguesa e memes de internet: outros textos, outras leituras. As autoras discutem sobre o trabalho com textos multimodais e multissemióticos - a exemplo dos memes de intenet - no ensino de Língua Portuguesa, na Educação Básica, e concluem que esse tipo de atividade é de suma importância para criar oportunidades para os estudantes atuarem, de forma mais autônoma, sobre as mídias digitais, sustentando suas opiniões e desenvolvendo argumentos nesses espaços emergentes, possibilitando a ampliação de ações discursivas, tendo em vista uma racionalidade comunicativa.

Mellissa Moreira Figueiredo Barbosa, José Railson da Silva Costa e Milenna Brun, da UEFS, são os autores do artigo intitulado Competência comunicativa e letramento crítico: formação de professores de língua estrangeira para a cidadania e inclusão social. O estudo apresenta o processo de desenvolvimento da competência comunicativa e das práticas de letramento crítico no âmbito das turmas de língua inglesa do Programa de Extensão Portal: ensinoaprendizagem de línguas para a cidadania, inclusão social e diálogo multi e intercultural, da Universidade Estadual de Feira de Santana, em 2016, como também o percurso de elaboração de dois módulos didáticos autênticos, aplicados no referido programa.

Elza Rodrigues Barbosa Peixoto, Maria José de Pinho, ambas da Universidade Federal do Tocantins, são autoras do artigo intitulado Literatura na Hora Certa, um pacto para o letramento literário? Uma análise da proposta de formação do Pnaic. No texto, as autoras discutem e analisam discursivamente a ação de formação do professor alfabetizador, trazida pelo PNLD/PNAIC na edição 2015, através do Guia de Literatura na Hora Certa, com o objetivo de verificar se as concepções ideológicas que perpassam os discursos da referida ação de formação entram em conjunção com o que nos propõem os estudos do letramento literário e de investigar quais imagens de escolarização literária projetam em seu discurso. As autoras concluem que - no percurso temático da literatura na alfabetização - marcar as séries iniciais como a hora certa da literatura foi o fio condutor da proposta-guia, reiterada nas diversas vozes que compuseram esse discurso.

O artigo Haicai: Sequência Didática na perspectiva do Letramento Literário é de autoria de Walmeria Oliveira Dantas e de Alana de Oliveira Freitas El Fahl, da Universidade Estadual de Feira de Santana. O texto é um recorte da dissertação de mestrado defendida em 2016, no ProfLetras/UEFS. A pesquisa - de base qualitativa, com foco na pesquisaação - apresenta uma proposta de intervenção baseada na metodologia de sequência didática aplicada à leitura e à escrita de haicais, inspirados em fotografias autorais. $\mathrm{O}$ objetivo da pesquisa foi contribuir para o aumento dos níveis de letramento literário de uma turma de alunos do sétimo ano do Ensino Fundamental.

Márcio Alessandro de Oliveira, da Universidade do Estado do Rio de Janeiro, é autor do artigo intitulado O gótico no livro Literatura Brasileira: em diálogo com outras literaturas e outras linguagens. Trata-se de um estudo acerca da presença do gótico no livro didático 
Literatura Brasileira: em diálogo com outras literaturas e outras linguagens. O objetivo do artigo é investigar o tratamento dispensado à estética gótica no referido manual.

$\mathrm{O}$ artigo $\mathrm{O}$ ensino de lingua portuguesa a partir do uso do livro didático: um olhar reflexivo sobre as atividades de compreensão e interpretação, de autoria de Bárbara Muders, da Universidade Federal de Santa Maria, e Ana Cecilia Teixeira Gonçalves, da Universidade Federal da Fronteira Sul, tem o objetivo de apresentar uma análise de atividades de compreensão e interpretação vinculadas a gêneros textuais, propostas em unidades de um livro didático de Língua Portuguesa. Busca-se identificar se as atividades de compreensão e interpretação abrem espaço para a interação entre falante e ouvinte ou se conduzem o processo de compreensão e interpretação apenas de modo mecânico, em que a língua é vista como um código, como um processo fechado. As autoras concluem que as atividades de compreensão e interpretação devem estar centradas no processo de interação verbal, uma vez que essa concepção possibilitará que o sujeito produza enunciados pensando sempre na compreensão e na resposta ativa do outro, porquanto é nessa relação que o conhecimento ocorre de fato.

O professor de línguas, o PNLD, o livro didático de línguas e outros materiais didáticos é o título do artigo de autoria de Renato Caixeta da Silva, do Centro Federal de Educação Tecnológica de Minas Gerais. A partir de uma reflexão acerca do Programa Nacional do Livro Didático (PNLD), o autor problematiza as situações e as demandas que o professor de línguas tem enfrentado atualmente e as confronta com as relações entre o professor, o livro didático e outros materiais de ensino no seu cotidiano profissional. A pesquisa está ancorada nas discussões fomentadas nos últimos anos pelo Grupo de Pesquisa em Materiais e Recursos Didáticos do CEFET-MG.

Alba Krishna Topan Feldman e Luiz Sérgio Alzair Alzão, da Universidade Federal de Maringá, são os autores do artigo O filme diary of a wimpy kid no ensino da língua inglesa. $\mathrm{O}$ objetivo do estudo é destacar a funcionalidade da imagem como modalidade de construção de significados e apresentar sugestões de letramento, com o uso de filmes, no ensino da língua inglesa, no Nível Fundamental.

Lívia Carvalho Mendonça e Ligia Pellon de Bulhões, da Universidade do Estado da Bahia, são autoras do artigo Português e Redação: imprecisão de duas disciplinas em uma disciplina só. As autoras abordam a imprecisão dos currículos do Ensino Fundamental II regular, de escolas públicas baianas que ofertam as disciplinas Redação e Língua Portuguesa ou apenas Língua Portuguesa. Elas se baseiam em entrevistas feitas com professores de português da Rede Pública de Educação do Estado da Bahia. Concluem que as incongruências dos currículos para o ensino de português refletem a inadequação dos objetivos que estão postos pelo sistema escolar.

$\mathrm{O}$ artigo Pedagogy of Multiliteracies and Argumentation: An Online Attempt in the Letras Course, em língua inglesa, é de autoria de Najin Marcelino Lima e Maria Cristina Damianovic, da Universidade Federal da Paraíba. No artigo, os autores analisam uma proposta de reforma curricular, que foi realizada num curso híbrido oferecido aos alunos do curso de Letras na UFPE. Eles concluem que um curso baseado nos estudos de 
multiletramentos é mais propenso a oferecer espaços nos quais uma argumentação colaborativa possa ser desenvolvida.

Iranildes Almeida de Oliveira Lima, da UEFS, e Luana Moreira Reis, da University of Pittsburgh, são autoras do artigo Princípios teórico-metodológicos para elaboração de material didático de PLE e a necessidade de inclusão sistemática dessa discussão nos currículos de formação de professores. No texto, as pesquisadoras discutem os conceitos de material didático, apresentam os princípios teórico-metodológicos que norteiam a elaboração de materiais didáticos no âmbito de um programa de ensino-aprendizagem de línguas na UEFS e com base na análise de fluxogramas e ementas de disciplinas dos cursos de licenciatura em letras de universidades brasileiras - destacam a necessidade de incluir essa discussão nos cursos de formação de professores de línguas.

$\mathrm{O}$ artigo Por uma prática de leitura e escrita: uma experiência com o gênero fábula é de autoria de Jeane Maria Favorino e Alana de Oliveira Freitas El Fahl, da Universidade Estadual de Feira de Santana. No artigo, elas apresentam e discutem os resultados de uma proposta de intervenção pedagógica aplicada na Escola Estadual Antônio Carlos Pedreira, localizada no município de São Gonçalo dos Campos, no Recôncavo Baiano. A proposta teve como objeto de ensino a mobilização do gênero fábula, visando a proporcionar aos alunos do $6^{\circ}$ ano do Ensino Fundamental II oportunidades para desenvolverem sua competência discursiva. Trata-se de parte da pesquisa desenvolvida como dissertação de mestrado no ProfLetras/UEFS.

O artigo Regimes de interação em práticas de inclusão de deficientes visuais é de autoria de Elza Rodrigues Barbosa Peixoto e Luiza Helena Oliveira da Silva, da Universidade Federal do Tocantins. Os autores analisam o trabalho pedagógico de perspectiva inclusiva, fundamentada nos estudos da semiótica discursiva greimasiana, centrada mais especificamente na sociossemiótica de Eric Landowski. Eles mobilizam os regimes de interação e sentido, tendo como corpus de análise o relatório de adaptação de alunos com necessidades especiais, produzido pelo setor de Psicologia de um escola, fundamentado em relatos de impressões e considerações gerais apontadas por cada parte envolvida no processo: professores, coordenação e aluna deficiente visual total e sua mãe.

Alexandre Melo de Sousa e Ana Paula Teixeira Gouveia, da Universidade Federal do Acre, são os autores do artigo intitulado Toponímia e memória: uma proposta de atividade para as aulas de Lingua Portuguesa no Ensino Médio. Eles apresentam uma proposta de atividade para as aulas de língua portuguesa no Ensino Médio, a qual dialoga com a Toponímia e com a perspectiva da memória oral, na intenção de dar abertura para a contemplação de um gênero textual ligado à linguagem cotidiana de pessoas de diversas ocupações sociais. Concluem que a relação entre Toponímia e memória pode criar uma aproximação entre alunos e comunidade, como preconizam as Orientações Curriculares para o Ensino Médio. Trata-se de uma pesquisa inovadora e criativa, que aplica conhecimentos teóricos sobre a toponímia ao ensino de Língua Portuguesa.

Translinguajamento: pensando entre línguas a partir de práticas e metadiscursos de docentes indígenas em formação superior é o artigo de autoria de Denise Pimenta de Oliveira e André Marques do Nascimento, da Universidade Federal de Goiás (UFG). O artigo apresenta 
uma pesquisa que tem o objetivo de estabelecer a genealogia epistemológica do conceito de translinguajamento - a partir de pressupostos teóricos do campo dos estudos decoloniais - e de compreendê-lo com base em práticas comunicativas e metadiscursos de docentes indígenas em formação superior específica na UFG.

$\mathrm{O}$ artigo Webletramiento: cronotopías, exotopías, desafíos contemporáneos del profesor de E/LE, escrito em língua espanhola, é de autoria de Robério Pereira Barreto, da Universidade Estadual de Feira de Santana. O autor aborda os desafios contemporâneos presentes no treinamento de professores E/LE. Com base em algumas questões teóricas sobre as novas necessidades exigidas pela formação de professores E/LE, Robério Barreto propõe que - por meio do uso didático e pedagógico dos instrumentos tecnológicos e digitais conectados - é possível expandir as estratégias de ensino e as habilidades dos alunos para aprender uma língua estrangeira.

Haja vista a diversidade dos temas abordados e a qualidade das pesquisas, julga-se que este número da revista $A$ cor das Letras traz uma importante contribuição aos estudos sobre o ensino de línguas e literaturas na Educação Básica.

Os editores

Flávia Aninger de Barros Rocha Mariana Fagundes de Oliveira Lacerda

Patrício Nunes Barreiros

Silvana Silva Farias de Araújo 